than in the great and historic institutions from which these Christmas greetings come. The more profoundly do we appreciate their noble and moving recognition of our endeavour, together with the other Universities of Great Britain, to maintain the continuity of scholarship and to keep, even in these days, the standards of knowledge unimpaired and the sources of truth unsoiled."

\section{University of London Certificate in Natural History}

JusT before the outbreak of war, the University of London, in response to an expressed demand, instituted a Certificate of Proficiency in Natural History, designed for teachers who require an additional qualification testifying that they have a practical working knowledge of natural history such as will be of special value in teaching it to children up to the age of fifteen. The necessary studies involved attendance at a course of lectures and laboratory work of about three hundred hours' duration, together with a certain amount of organized field-work. Considerable interest was shown in the University's new departure, and some education authorities were prepared to arrange suitable courses : but the dislocation of the school teaching services all over the country has brought about the result that the courses of study contemplated by the University are not suited to the present-day circumstances of teachers.

Consideration has therefore been given to the possibility of devising some special emergency regulations which would meet the intention of the original requirements and make the best use of the fact that large numbers of urban schools are now located in the country or at the seaside, and so presented with an opportunity of natural history study in the field which, under normal peace-time conditions, would have been impossible; as a result emergency regulations have been drafted. The main principles of the proposed new regulations are: $(a)$ to substitute for the present lecture-laboratory requirement a directed course of private reading together with attendance at a fortnight's summer vacation course arranged by the University, and $(b)$ to take advantage of the teacher's probable extended period of residence in rural conditions by putting the main emphasis on the work in the field, involving the writing under expert advice of a substantial essay on some specialized topic chosen by the student. At the moment, however, the University has no evidence as to how far such a scheme would be welcomed by those teachers who might have been expected under normal conditions to have studied for the original Certificate. Any teacher, therefore, who is interested in the proposed new scheme as outlined is invited to communicate with the University Extension Registrar, University of London, at Royal Holloway College, Englefield Green, Surrey.

\section{A War-Time Formulary}

IN view of the urgent need for a comprehensive war-time formulary for the guidance of medical prescribers, it is satisfactory to learn that, at the instigation of the Ministry of Health, a strong and representative committee has been set up for the purpose of providing such a formulary for use during the emergency. The following bodies have been invited to appoint representatives: the Royal College of Physicians, the Pharmacopoeia Commis. sion, the British Medical Association, the Pharmaceutical Society, the National Pharmacists Union and the Wholesale Drug Trade Association. It is understood that the Committee intends to complete its work as speedily as possible. The publication of this formulary will be welcomed by medical men and dispensers, who are at present without an official guide as to the best substitutes for drugs which are now almost unobtainable and the best methods of compounding them for administration to patients. Apart from the few additions to the monographs of the British Pharmacopoia and alterations of a few monographs and lists of scarce drugs and suggested substitutes prepared by the Medical Research Council, no attempt has hitherto been made to compile a comprehensive book of formulæ for use during the period of emergency.

\section{New Winter Forage Grasses}

WINTER forage in Great Britain is a matter of first importance to the farmer and any new methods of ensuring a supply are worthy of careful consideration. W. Davis has brought forward the suggestion ( $E m p$. J. Agric., 8, 289; 1940) that pampas and tussac grasses, although exotic species, might profitably be grown for this purpose. Pampas grass (Cortaderia selloana) is a common ornamental plant in Britain, and though its leaves are coarse and harsh, it appears to be surprisingly palatable. It is both winter green and able to withstand drought, so that it would be productive just when other pasturage is short, and further, its tussock-forming habit would be specially valuable on hill pastures during periods of snow. The use of pampas grass has recently been investigated in New Zealand, where the results are promising.

Establishment from seed is slow, and it is probably best raised under nursery conditions and not grazed for at least a year. Chemical analyses show that it is considerably less nutritive than clover or young grass, but its relatively high yield (50 tons per acre per annum) and the fact that it is consumed in situ, thus avoiding labour costs, are compensating features. Tussac grass (Poa flabellata) is a much-prized forage plant in the Falkland Islands. Like pampas grass it is slow to establish, but once the initial stand is secured, the crop should go on indefinitely. In its natural habitat (the sea coast), this grass shelters numerous birds and seals, whose trampling and scratching cultivates the soil, while their excreta act as manure; inland the domestic fowl serves the same purpose. This combination of plant and animal life appears to be of fundamental importance to the healthy maintenance of the tussac plant. There seems no reason why these two grasses should not flourish in Great Britain, and both would probably merit a trial, as they would prove a valuable asset when the usual types of winter feed are scarce. 